\title{
Las resistencias de los subalternos en la historiografía del Caribe
}

\author{
Pedro L. San Miguel*
}

\section{Resumen}

Este artículo forma parte de un trabajo más amplio en el que se discuten los grandes ejes temáticos o "metarrelatos" de la historiografía del Caribe. De esos grandes relatos, el tema de las resistencias de los subalternos ocupa actualmente un lugar preeminente en la historiografía caribeña. Este ensayo examina la evolución del mismo, destacando cómo las transformaciones políticas, sociales y culturales de los países del Caribe han contribuido a convertirlo en un aspecto central de su historiografía.

\section{Abstract}

This article is part of a broader study that discusses the great themes or "meta-stories" of Caribbean historiography. Among these "meta-stories", currently the theme of the subalterns' resistances plays a preeminent role in Caribbean historiography. This essay traces the evolution of the theme of resistance, highlighting how political, social and cultural transformations in the Caribbean have contributed in making it a central aspect of its historiography.
Palabras clave:

Caribe, historiografía, resistencias, subalternidad, esclavitud, resistencia.
Fecha de recepción: marzo de 2001

Fecha de aceptación: mayo de 2001

* Profesor titular en el Departamento de Historia de la Universidad de Puerto Rico-Río Piedras. Correo electrónico: psanmig@prw.net 
HISTORIAS DE PODER, HISTORIAS DE OPOSICIÓN

$\mathbf{L}$

a historia del Caribe se podría escribir en torno a la historia del poder. Mas la cuestión del poder remite a las oposiciones a la dominación, a la autoridad, a la exacción, a la jerarquía y a la coacción. Es decir, remite a las resistencias, a ese multifacético y complejo conjunto de actos de los sectores o grupos subordinados -ya sea por razones de clase, de origen, étnico-raciales o de género- con el propósito de mitigar o rechazar las exigencias de los sectores hegemónicos o dominantes, del Estado o de cualquier otra fuente de poder que realice tales demandas o que intente imponerse por la fuerza, la violencia o la coerción. ${ }^{1}$ Vinculadas desde sus orígenes a diversas formas de opresión y subordinación, las utopías en el Caribe han existido en una tensión constante entre la opresión y las resistencias. Se puede argumentar que la historia del Caribe se inició con un acto de imperio. En un típico gesto de poder -porque, después de todo, conferitle nombres a las cosas es una manera de apropiárselas-, Colón llamó San Salvador a la isla que sus habitantes llamaban Guanahaní, Juana a Cuba, y Española a la isla que hoy comparten Haití y la República Dominicana. Este acto de enunciación preludió la apropiación de los territorios del Caribe por las potencias europeas y la sujeción de sus poblaciones, acciones ambas que generalmente con-

1 Esta definición está basada en Scott, Weapons, 1985. Del mismo autor, véase Domination, 1990. llevaron cambios de nombre. Parecía imposible alcanzar la gloria llamándose Anacaona, Hatuey o Caguax. Llamarse María, Juan o José brindaba ventajas innegables para ganarse el cielo.

Las crónicas de los conquistadores contienen numerosos relatos de las resistencias que opusieron los aborígenes del Caribe a los recién llegados, que pronto se convirtieron en sus opresores. Esas narraciones van desde la temprana andanada de flechazos que, durante su primer viaje, recibieron Colón y sus acompañantes en el llamado golfo de las Flechas, en la isla Española, hasta la fiera resistencia que opuso una anónima mujer indígena al ataque sexual del que fue objeto en el segundo viaje, suceso que conocemos gracias a Diego Álvarez Chanca, físico de la expedición y perpetrador de tan singular "encuentro de dos mundos". ${ }^{2}$ A medida que se incrustó el dominio español, los cronistas narraron las rebeliones de los indígenas. Atribuidas a su ruindad, su maldad, su naturaleza "ingrata" y sus "malas inclinaciones y obras", ${ }^{3}$ las sublevaciones de los indios antillanos recibieron la condena unánime de los cronistas, a excepción de Las Casas quien se preguntaba, ante las crueldades e iniquidades cometidas por los conquistadores, si no tenían los

2 "Carta del físico Diego Álvarez Chanca al Cabildo de Sevilla dándole cuenta del segundo viaje de Cristóbal Colón, 1493" en Caro Costas, Antología, 1983, pp. 25-27.

3 "Fragmentos de la Historia general y natural de las Indias por Gonzalo Fernández de Oviedo 1535..." en Fernández Méndez (comp.), Crónicas, 1970, p. 42. 


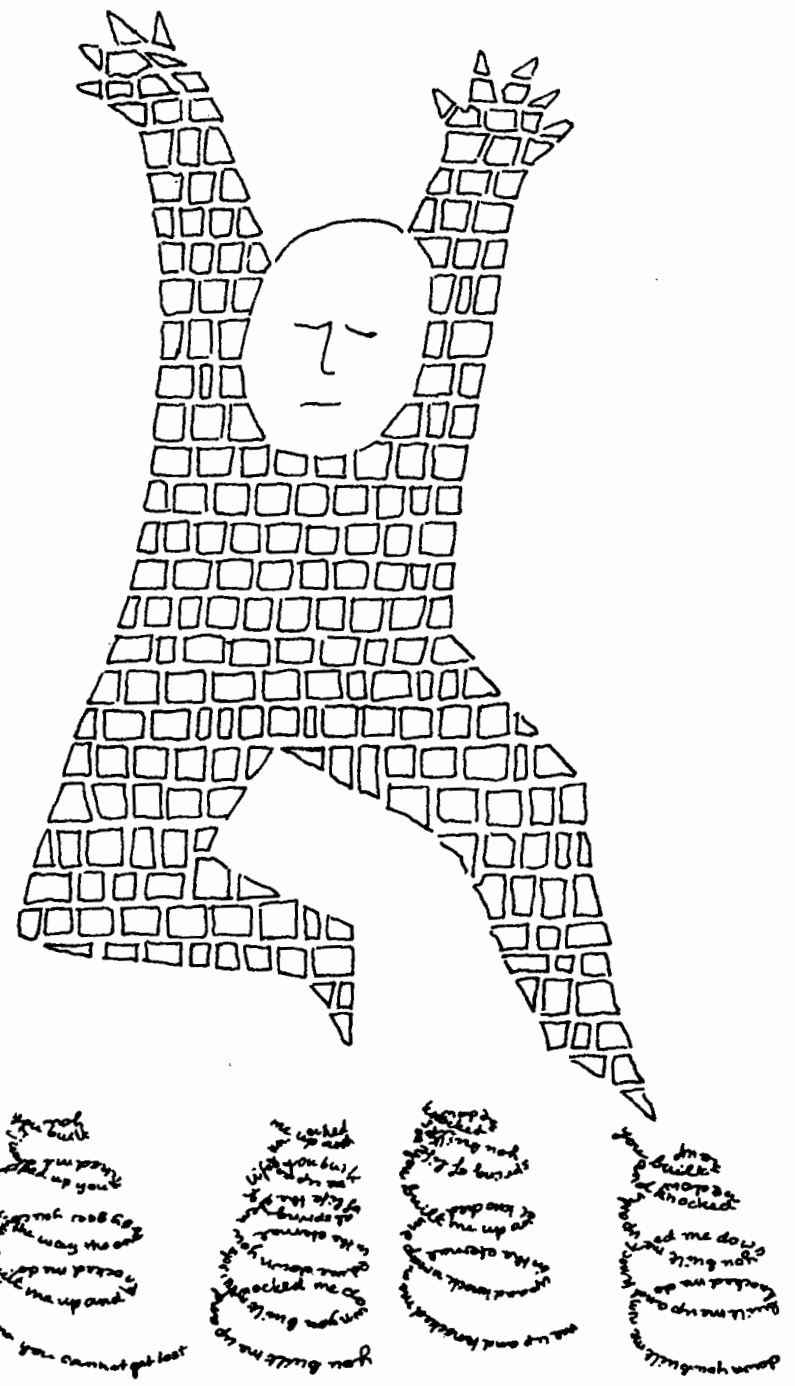


aborígenes "justo título y derecho para contra los cristianos mover y sostener justa guerra". ${ }^{4}$ Similar condena recibieron los ataques de los supuestos indios caribes y, posteriormente, los levantamientos de los esclavos africanos, convertidos en sostén de la economía antillana a raíz del exterminio de la población indígena. Desde la óptica "civilizadora" de los europeos de los siglos XVI y XVII, las rebeliones de los indígenas y los esclavos eran una muestra más de su salvajismo.

\section{LA VISIÓN DE LA PATRIA CRIOLLA}

Interesantemente, esta concepción prevalecería por los siguientes siglos -en ocasiones, hasta el mismísimo siglo $\mathrm{xx}-$, por lo que permeó los escritos de los primeros cronistas e historiadores criollos. Herederos ideológicos de la conquista y de los esquemas de explotación instaurados a partir de entonces, la intelligentsia colonial suscribió en lo fundamental la visión de los conquistadores. A lo sumo, desarrollaron una visión dual de sus respectivas metrópolis. Por un lado, estaba la "madre patria" sublime, hidalga, llena de "elevadas miras", portadora de los más altos valores de la civilización y dispensadora de esa identidad que en las colonias confería un sentido de superioridad. Por el otro, estaba la metrópoli "mezquina", representada por burócratas corruptos y venales y por inmigrantes ambiciosos que aspiraban

${ }^{4}$ Biblioteca, 1988, p. 378. Para una síntesis de las rebeliones indígenas, véase Cassá, Indios, 1992, pp. 241-257. a arrebatarle a los criollos de abolengo lo que éstos consideraban que eran sus legítimos derechos sobre las colonias. ${ }^{5}$ Pero en lo que respecta a las clases subalternas, las elites y los letrados criollos suscribieron las concepciones que surgieron en la temprana época colonial. Los intereses económicos, amén de los criterios de la "raza", el color y la cultura -definida en lo fundamental en términos de la religión y la lengua-, generaron un fuerte sentido de solidaridad entre los criollos de las clases altas y medias y los sectores metropolitanos. A sus ojos, las rebeldías de los esclavos representaban un peligro a sus intereses económicos, al orden colonial y a la civilización cristiana misma.

En sus narraciones históricas, los letrados criollos resaltaron aquellos antagonismos con los sistemas coloniales que sustentaban y validaban sus reclamos políticos; es decir, pusieron énfasis en los conflictos que se referían a sus propias querellas contra los poderes metropolitanos. ${ }^{6}$ Con frecuencia, al calor de tales conflictos las elites criollas iniciaron su estudio de la historia, travesía hacia el pasado que pretendía identificar los albores de una nueva identidad, y "descubrir" las justificaciones éticas para impugnar un orden colonial que, desde su perspectiva, se tornaba cada vez más injusto. ${ }^{7} \mathrm{La}$ reflexión histórica criolla se originó en

5 Este argumento está basado en Martínez, Patria, 1975, pp. 50-51.

“Álvarez, “Afán”, 1998.

7 Al respecto, véase San Miguel, Isla, 1997, pp. 36-44; González, "Literatura", 1979, pp. 4579, y Castro, "Salvador", 1988-1989, pp. 9-35. 
un programa de regeneración política. El producto fue una narrativa que trazaba la "genealogía" nacional y cuyos "héroes" eran aquellas figuras que habían marcado el surgimiento de las nuevas identidades comunitarias. Los nudos de su trama eran los hechos fundacionales de la "comunidad imaginada" por los criollos, y los conflictos y las resistencias que habían protagonizado esas figuras prometeicas. ${ }^{8}$

En esas narrativas históricas los sectores subalternos no desempeñaban ningún papel significativo; como mucho, eran la "materia prima" que usaban los sectores dominantes para elaborar sus proyectos sociales y políticos. Carentes de miras e iniciativas propias, las masas se circunscribían a seguir a los sectores dirigentes. En el peor de los casos, constituían un verdadero lastre al proyecto político de las elites. Tales concepciones fueron comunes entre los letrados caribeños de principios del siglo $\mathrm{xx}$, independientemente de sus posiciones políticas. Radicales, moderados y conservadores pensaban que las masas debían seguir el dictamen de los "próceres". Carentes las clases populares de capacidad contestataria, sin nociones precisas sobre la identidad y sin horizontes políticos, según tal concepción la misma regeneración de las masas sería tarea de un "escaso número de hombres puros y conscientes" dispuestos a sacrificarse por patriotismo y por "deber". ${ }^{9}$ Esta fue la tónica predominante en las investigaciones históricas hasta muy entrado el siglo Xx. Definida la política

\footnotetext{
${ }^{8}$ Lugo-Ortiz, Identidades, 1999.

9 Bosch, "Pueblo", 1974, p. 7.
}

a partir de los criterios de las elites, los ámbitos de acción de las clases subalternas eran marginados de las reflexiones y las investigaciones históricas. Las mismas luchas anticoloniales fueron interpretadas fundamentalmente desde la óptica de las elites. ${ }^{10}$

\section{LAS RESISTENCIAS DE LOS SUBALTERNOS}

La obra que inició la inserción de las clases populares en las interpretaciones históricas se refiere, y no por casualidad, a Haití, primer país del Caribe en convertirse en una nación independiente, y cuya libertad fue consecuencia de una revolución social que conmocionó a toda América. The Black Jacobins, de C. L. R. James, publicada en 1938, representa un verdadero hito en la historiografía caribeña debido a que rompió con los modelos narrativos prevalecientes. En primer lugar, porque en ella las masas ocupan el papel más destacado, no empece la relevancia que James le brindó al liderato revolucionario, en especial a Toussaint L'Overture. En consecuencia, James logró transmitir cabalmente "su creencia de que la gente común posee una capacidad extraordinaria para lograr cosas excepcionales", como demoler la principal economía esclavista del Caribe en el siglo XVIII y destruir el sistema colonial sobre el cual se sostenía y, a la vez, al que nutría. En segundo lugar, por-

10 Para críticas a este tipo de historia elitista en contextos coloniales, véase, Spivak, "Subaltern", 1988, y Guha, "Some", 1988, pp. 3-32 y $37-44$, respectivamente. 
que el foco de James es decisivamente el Caribe, no los centros metropolitanos. ${ }^{11}$ Estos rasgos sobresalientes de la obra de James evidencian que su visión del Caribe giraba en torno a dos corrientes históricas, a dos grandes vertientes de las luchas caribeñas por la libertad: a las luchas de los sectores populares por obtener una mayor justicia social y a las luchas en contra del colonialismo. Es decir, en la obra de James convergieron dos vertientes de la historia de las resistencias en el Caribe que pocas veces habían coincidido.

No obstante, la perspectiva inaugurada por James tendría que esperar varias décadas para adquirir legitimidad y para convertirse en una de las tendencias más vigorosas, creativas y enriquecedoras de la historiografía caribeña y de su producción intelectual en general. Relacionada obviamente con las reformulaciones sobre la identidad que ocurrieron a partir de los años cincuenta y con los proyectos políticos y sociales concomitantes a éstas, a partir de los años setenta las luchas y las resistencias de los subalternos se convirtieron en los núcleos de la historiografía caribeña. Inspiradas en las corrientes políticas radicales que proliferaron en esos años, que le confirieron un lustre especial a las gestas revolucionarias y a los movimientos que confrontaban directamente a las estructuras de poder, dos de las vertientes de las luchas populares que más llamaron la atención de los historiado-

11 Knight, "Race", 1999, pp. 223-224, y Scarano, "Slavery", 1999, pp. 249-251. Sobre James, véase Henry y Buhle (comps.), James's, 1992. res fueron las rebeliones de los esclavos y el cimarronaje. ${ }^{12}$

$Y$ era de esperarse que así fuera. Convertida la esclavitud en una de las "palabras clave" (keyword) de la historia caribeña, en uno de esos términos o conceptos que han articulado la discursiva sobre su pasado, fungiendo como metáfora de la opresión y la explotación que ha sufrido la región, las luchas contra ella se convirtieron en parte de un discurso redentorista que constituía una alegoría de sus luchas por la libertad. Igualmente, y dado el clima de los años sesenta y setenta, cuando parecía que la batalla final de los "condenados de la Tierra" era inminente, las investigaciones sobre las rebeliones, las conspiraciones y las resistencias abiertas de los esclavos actuaban como una suerte de "demostración" tanto de la legitimidad ética de esas formas de lucha, que conllevaban el uso de la violencia, como de la posibilidad de que ellas contribuyeran a la destrucción de las cadenas de la opresión. Debido, sobre todo, a las influencias del marxismo, las fugas, las cimarronadas y las rebeliones de los esclavos fueron vistas como parte de esas luchas de clase que eventualmente llevarían a la total supresión de la explotación económica y a la redención de los trabajadores. De igual forma, no obstante constituir los

1.2 Scarano, "Slavery", 1999, pp. 272-275. Entre la numerosa bibliografía sobre estos temas, se pueden consultar, Price (comp.), Marron, 1973; Barnet, Biografia, 1979; Campbell, Maroons, 1990; Hart, Esclavos, 1984; Patterson, Sociology, 1967; Craton, Testing, 1982; Fouchard, Marrons, 1988; Baralt, Esclavos, 1982, y Genovese, Rebellion, 1981. 
esclavos una clase "premoderna" y de constituir sus luchas formas "prepolíticas" de resistencia a la opresión, ${ }^{13}$ éstas habrían contribuido a debilitar a los regímenes coloniales y a socavar su infraestructura económica. Además, habrían sido agentes catalíticos en el surgimiento de los cuestionamientos morales e ideológicos de la esclavitud que se suscitaron tanto en las colonias como en las metrópolis. ${ }^{14}$

Fueron múltiples las reverberaciones y las implicaciones ideológicas del estudio de las revueltas de los esclavos. Son palpables, por ejemplo, sus nexos culturales con los movimientos de la negritud, del Black Power, del "retorno a Africa" y de las luchas por los derechos civiles. También es evidente su relación con las luchas anticoloniales en el Caribe, África y Asia, en especial con sus manifestaciones ideológicas, como las obras de Frantz Fanon y Albert Memmi. ${ }^{15}$ Debido, por otro lado, a que el estudio comparativo de los sistemas esclavistas de las Américas demostraba que las sublevaciones y las revueltas de los esclavos fueron más frecuentes e intensas en los países de América Latina y el Caribe que en Estados Unidos, ${ }^{16}$ esto sugería la correc-

13 Uso la conceptualización que popularizó Hobsbawm en Primitive, 1965.

${ }^{14}$ Sobre el particular son fundamentales las obras de Davis, sobre todo: Problem, 1966; Problem, 1975, y Slavery, 1984. Ese nexo entre las luchas sociales y las concepciones ideológicas es explorado de forma brillante en Holt, Problem, 1992.

15 Fanon, Condenados, 1972; ;Escucha!, 1970, y Memmi, Retrato, 1969.

${ }^{16}$ Genovese, Rebellion, 1981. ción de las teorías acerca del papel revolucionario de los países del tercer mundo vis-a-vis Europa y Estados Unidos. En otras palabras, concordaba con la noción, entonces en boga, de que la revolución se movía de la "periferia" hacia el "centro", o del "campo" hacia la "ciudad”. En el ámbito historiográfico, las investigaciones sobre las rebeliones de los esclavos constituyeron un poderoso mentís a las tesis sobre la benevolencia de los sistemas esclavistas en los países colonizados por España y Portugal frente a una supuesta mayor rudeza y crueldad de los demás regímenes esclavistas. ${ }^{17}$

Los estudios sobre las rebeliones esclavas constituyeron la punta de lanza de un nuevo paradigma histórico en el cual las clases subalternas ocupaban el lugar central. Ello fue así tanto en lo que respecta a las clases premodernas, como los esclavos y los campesinos, como a las clases modernas. En diversos países del Caribe se realizaron investigaciones sobre el surgimiento $y$ las luchas del proletariado, tanto en sus versiones urbanas como rurales. ${ }^{18}$ En consecuencia, las historias nacionales pasaron a concebirse a partir de la evolución de sus respectivas clases trabajadoras; sus luchas y sus expresiones culturales se convirtieron en los ejes in-

17 En torno a este debate, véase Tannenbaum, Slave, 1946; Elkins, Slavery, 1963; Foner y Genovese (comps.), Slavery, 1969; Genovese, World, 1971, y Klein, Slavery, 1967.

${ }_{18}$ Cross y Heuman (comps.), Labour, 1988; Haraksingh, "Labour", 1999, pp. 283-307; García y Quintero Rivera, Desafío, 1982; VV. AA., Obreros, 1975; Cabrera, Movimiento, 1969; Viven, 1985, y Cassá, Movimiento, 1990. 
terpretativos de la historia caribeña. Así, para Walter Rodney la historia de Guyana se sintetiza en la historia de sus sectores trabajadores; de igual forma, para Ángel Quintero Rivera los enigmas de la política puertorriqueña a principios del siglo XX encuentran su explicación al desentrañar "la otra cara de la historia", la historia de las clases trabajadoras. ${ }^{19}$ De haber estado ausentes en las narraciones históricas, los sectores subalternos pasaron a ser los "héroes" de las "épicas naciónales" que produjeron las "nuevas historias" que surgieron en el Caribe en los años setenta.

A tono con esta corriente, se ampliaron los temas de investigación, abarcando aspectos de la vida de los sectores populares que previamente habían quedado fuera de la historiografía. Al respecto, las influencias de la antropología resultaron cruciales, ya que, debido a su tradicional énfasis en lo premoderno, en lo exótico y en la vida cotidiana, había prestado gran interés a los sectores populares. ${ }^{20}$ Esto es palpable en las tendencias más recientes en los estudios sobre los sectores subalternos del Caribe; por ejemplo, en las investigaciones sobre la historia de las mujeres. Concentrados en los temas más convencionales de la historia -la política y la economía-, originalmente proliferaron los estudios sobre la participación de las mujeres en la producción y el comercio, y en cómo fueron ganando espacios en la vida pú-

19 Rodney, History, 1981; Quintero Rivera, Conflictos, 1976; Patricios, 1988, y González y Quintero Rivera, Otra, 1984.

20 San Miguel, "Falsos", 1999, pp. 33-61, y Steward et al., People, 1966. blica, incluso en la política formal. ${ }^{21}$ La teoría subyacente a tales investigaciones era que las mujeres sólo alcanzaban su autonomía personal rompiendo con los espacios domésticos, que su emancipación se lograba en las esferas de lo público. No obstante, este modelo ha sufrido modificaciones a medida que han florecido las investigaciones sobre el género, la organización familiar y la sexualidad, que han cuestionado las separaciones tajantes entre lo público y lo privado. Como ejemplo hay que mencionar el trabajo pionero de Verena Martínez sobre las relaciones raciales y los valores sexuales en la Cuba decimonónica. ${ }^{22}$ En este estudio, que combina la historia y la antropología, se demuestra que no existe tal separación entre lo público y lo privado; que hasta lo más íntimo, como la selección de pareja y la sexualidad, posee implicaciones públicas, y que, por otro lado, los determinantes sociales, como las percepciones sobre la raza y el "color", inciden sobre los comportamientos más personales y recónditos. Incluso, las relaciones entre las parejas y los valores sexuales y familiares producen discursos y prácticas que trascienden esos espacios, y que generan relaciones de poder en el ámbito de la polis, en la comunidad político-social en que se insertan. ${ }^{23}$

21 Como muestras, véase Acosta Belén (comp.), Mujer, 1980; Baerga (comp.), Género, 1993; Barceló Miller, Lucha, 1997; Beckles, Natural, 1989; Bush, Slave, 1990, y Matos Rodríguez, Women, 1999.

22 Martínez-Alier, Marriage, 1974.

23 Stubbs, "Gender", 1999, pp. 95-135; Quiñones, "Hombre", 1997, pp. 30-42; Rodríguez, 
Esta aproximación al ámbito de lo privado, hacia los espacios de lo micro, ha conllevado reformulaciones sobre las resistencias. Pensadas originalmente en función de la tradición revolucionaria, que implicaba transformaciones económicas y sociales radicales, eventualmente comenzaron a despuntar otras expresiones de la oposición de los sectores subalternos a los esquemas de poder. Para decirlo de forma sintética, se comenzó a valorizar lo que James Scott ha denominado las "resistencias cotidianas", esas manifestaciones consuetudinarias de contraposición, conflicto, pugna, desafío, porfía y reto que se gestan y expresan de manera oculta, encubierta o discreta. "Armas del débil", ha llamado Scott con propiedad a tal tipo de resistencia, ya que responden a una relación de dominación en la que el equilibrio de fuerzas es tan desigual que impide o bloquea una oposición abierta y frontal. ${ }^{24}$ Estas resistencias cotidianas son, por lo demás, las formas de oposición más comunes, ya que no conllevan un cuestionamiento a la totalidad del orden imperante, por lo que pueden expresarse de manera espontánea en el curso de la vida habitual, y pueden asumir una enorme diversidad de manifestaciones -incluso simbólicas y alegóricas- y tramitarse por medios aparentemente inocuos e inofensivos.

Tal fue el caso, por ejemplo, de las múltiples formas en que los esclavos intentaron ganar espacios económicos,

"Mujeres", 1997, pp. 80-95; Flores, "Virgins", 1998, pp. 83-104, y Findlay, "Love", 1998, pp. 139-172.

${ }^{24}$ Scott, Weapons, 1985. sociales y culturales autónomos. En relación con el surgimiento de actividades económicas propias, fue Sidney Mintz quien primero insistió en el desarrollo de actividades "proto-campesinas" entre los esclavos, las que incluían el cultivo de pequeños pedazos de tierra, la crianza de animales y la venta de sus productos en los mercados locales. ${ }^{25}$ Tales prácticas constituyeron un verdadero espacio de lucha y de resistencia de los esclavos, quienes tuvieron que defender el tiempo que empleaban en dichas actividades y pugnar por obtener la movilidad que les garantizaba la venta de sus productos. ${ }^{26}$ Otras expresiones fueron aquellas acciones de los esclavos en los centros de trabajo que equivalían a un verdadero sabotaje del proceso productivo. ¿Cuánta, por ejemplo, de la indolencia, la negligencia, la incompetencia y la vagancia que los propietarios achacaban a sus esclavos eran parte de esa estrategia de lucha que conllevaba hacer lo menos posible? Con frecuencia, la resistencia tomaba formas más directas y se manifestaba en la destrucción de herramientas y maquinaria, o en el robo de los frutos. ${ }^{27}$ Por supuesto, estas formas de resistencia no fueron exclusivas de los esclavos. Los diversos sectores de las clases artesanales y proletarias emplearon formas similares de lucha, como se evidencia en las quemas de cañaverales

25 Mintz, Caribbean, 1984, pp. 131-224.

${ }^{26}$ Marshall, "Provision", 1991, pp. 48-67, y Beckles, "Economic", 1991, pp. 31-47.

27 Estas formas de resistencia han sido discutidas para Estados Unidos, si bien con una perspectiva comparativa, por Genovese en Economía, 1970, y Roll, 1976. 
durante el siglo $\mathrm{xx}$ y en la destrucción o el sabotaje de la maquinaria. ${ }^{28}$

Pero, ¿cuán efectivas han sido tales formas de lucha en modificar o trastocar los esquemas de explotación y subordinación impuestos por las clases dominantes? ¿Cuán significativas han sido en alterar los términos de la explotación, la obediencia y la sujeción? Quiero comenzar con lo que ya mencioné sobre la participación de los esclavos en la producción y en la venta de bienes, fenómeno que fue más común en el Caribe inglés y francés que en el hispano y el holandés. ${ }^{29}$ En primer lugar, estas actividades, si bien se desarrollaban en los márgenes de la economía de plantación, permitieron a los esclavos aumentar y diversificar su consumo de alimentos. De igual manera, les permitieron a algunos de ellos obtener pequeños ingresos monetarios que fueron usados para comprar su libertad o la de sus familiares. Visto desde una perspectiva macroeconómica y en la "larga duración", también fueron cruciales en el desarrollo de un mercado interno en algunos de los países del Caribe, como en Jamaica, donde estas prácticas se encontraban muy extendidas. ${ }^{30}$ Más aún, al decretarse la abolición de la esclavitud en los años treinta del siglo XIX, miles de libertos se lanzaron a comprar tierra, lo que no

28 Ramos Mattei, Sociedad, 1988; Taller, ¡Huelga!, 1982; Legrand, "Informal", 1995, pp. 555-596; Duarte Hurtado, Máquina, 1973, y Stubbs, Tabaco, 1989.

29 Scarano, "Slavery", 1999, p. 270.

30 Mintz, Caribbean, 1984; Higman, "Patterns", 1996, pp. 211-231; Hall, Eree, 1959, y Eisner, Jamaica, 1974. hubiese sido factible sin esa tradición de autonomía económica que habían desarrollado previamente. Esa tradición cimentó a ese campesinado negro que emergió en el Caribe británico luego de la abolición, el cual fue capaz de insertarse en la producción para el mercado y fue exitoso en la obtención de tierra. ${ }^{31}$ Como ha argumentado Thomas Holt, a través de sus acciones los esclavos, los libertos y sus descendientes fueron capaces de darle concreción a la noción abstracta de la libertad. Recurriendo, también, a peticiones discretas y comedidas a través de los organismos formales, como el sistema legal, hubo esclavos que alcanzaron la libertad, o que impugnaron la opresión que sufrían usando los mismos principios jurídicos, ideológicos y morales esgrimidos por los sectores dominantes y el Estado. ${ }^{32}$

La historia del campesinado caribeño también ofrece numerosos ejemplos de las implicaciones de las resistencias cotidianas. La misma existencia de las economías campesinas se puede considerar como una respuesta creativa al dominio de la plantación; de hecho, es uno de los pilares más importantes de la cultura de la "contraplantación". La lucha del campesinado por la tierra representa una de las expresiones concretas de esa tradición de oposición a la plantación. ${ }^{33}$ No obstante, la oposición al latifundismo es sólo

31. Mintz, Caribbean, 1984, pp. 157-179; Iolt, Problem, 1992, y Marshall, "Peasant", 1993, pp. 99-106.

32 Holt, Problem, 1992, y Scott, Slave, 1985.

33 San Miguel, Pasado, 1999, pp. 163-202 y 239-274. 
una de las formas de resistencia de los campesinos. Con frecuencia sus luchas económicas se han escenificado en ámbitos convencionales, como la producción para el mercado, pero en los cuales defienden su supervivencia. ${ }^{34}$ También se han esforzado por retener su fuerza de trabajo y por determinar en qué y cómo la emplean. Esto ha sido así, sobre todo, cuando los sectores hegemónicos y el Estado han intentado controlar el trabajo de los campesinos y de los trabajadores rurales con la intención de obtener mano de obra para sus latifundios o con el fin de construir obras públicas. Fernando Picó ha demostrado cómo, en el siglo XIX, los campesinos sin tierra de Puerto Rico fueron capaces, a través de una variedad de estratagemas, maniobras y subterfugios, de cotravenir las disposiciones del Estado para obligarlos a contratarse como jornaleros. ${ }^{35}$ Asimismo, durante la ocupación estadunidense de 1916-1924, los campesinos de la República Dominicana enfrentaron el trabajo obligatorio y las contribuciones establecidas a través de la evasión, el boicot y el ocultamiento. Así defendieron sus ingresos, su fuerza de trabajo y hasta sus tierras. ${ }^{36}$ En tiempos más normales, han protegido de igual forma sus ingresos y sus recursos en contra de los comerciantes, los intermediarios y los prestamistas. ${ }^{37}$

${ }^{34}$ San Miguel, Campesinos, 1997; Picó, Amargo, 1981, y Baldrich, Sembraron, 1988.

35 Picó, Libertad, 1983. Véase también Picó, Filo, 1993, y San Miguel, Mundo, 1989.

36 San Miguel, Pasado, 1999, pp. 203-237.

37 San Miguel, Campesinos, 1997, pp. 263 300, y Picó, Amargo, 1981.
Las resistencias de las clases subalternas en el ámbito cultural pueden ser tan significativas -o hasta más aúncomo las que operan en la esfera de lo material. La supervivencia de formas culturales de origen africano o su rearticulación en expresiones culturales de nuevo cuño, propiamente afrocaribeñas, es suficientemente elocuente para sugerir lo vigoroso de esas resistencias. Las religiones afrocaribeñas constituyen una de sus muestras más ricas y extraordinarias. ${ }^{38}$ Sin embargo, con frecuencia se obvian las conexiones entre las pugnas en torno a la producción simbólica y los conflictos económicos y políticos. En otras palabras, las resistencias de los subalternos en el ámbito cultural poseen una dimensión material que no se puede soslayar. ${ }^{39}$ Una de sus tácticas más comunes ha estribado en emplear los argumentos de los poderosos, pero interpretándolos desde su propia óptica, demostrando la hipocresía o la falsedad de las pretensiones de superioridad o de legitimidad de los grupos dominantes. ${ }^{40}$ Precisamente, uno de los aspectos más novedosos de los estudios sobre los sectores subalternos estriba en examinar las manifestaciones simbólicas y discursivas de sus resistencias. Este tipo de indagación debe contribuir a identificar sus concepciones sobre el poder, la historia, la cultura y las relaciones entre las clases.

38 Price-Mars, Habló, 1968; Schuler, "Myalism", 1980, pp. 65-79; Deive, Vodú, 1988; Martínez, Palma, 1991, y Sosa, Ñánigos, 1982.

39 Esta relación entre lucha social y cultura popular es examinada por Thompson en Making, 1966, y Tradición, 1979.

40 San Miguel, Pasado, 1999, pp. 239-274. 
Las expresiones discursivas de la subalternidad remiten a cómo se le da "voz" a los sectores subalternos en las narrativas históricas del Caribe, cuestión que cada día adquiere mayor relevancia debido a los debates contemporáneos en las ciencias sociales y la historiografía en torno al problema de la representación, a la posibilidad de personificar en nuestros textos las vidas y las experiencias de unos "Otros", de unos humanos que son distintos a "Nosotros" ${ }^{41}$ ¿Cómo "traducimos" al lenguaje letrado y académico unas experiencias que a fin de cuentas no nos pertenecen, que son ajenas? ¿Cómo justificamos el "apoderarnos" impunemente de esas vidas? ¿Con qué derecho nos "apropiamos" de esas vivencias, rebautizándolas con nuestros conceptos y nuestras categorías, para supuestamente volverlas más comprensibles e inteligibles? ¿Qué representamos en nuestros textos; cómo lo hacemos; para qué lo hacemos? ¿Cuánto de lo que hacemos estriba en apropiarnos del "Otro" para representarlo de acuerdo con nuestras particulares fábulas espaciales e identitarias?

\section{BiblografíA}

-Acosta Belén, Edna (comp.), La mujer en la sociedad puertorriqueña, Ediciones Huracán, Río Piedras, 1980.

41 Como obras experimentales que abordan esta cuestión, véase Price, First, 1990, y Alabi's, 1990. Entre las obras que debaten los problemas de la representación, véase De Certeau, Escritura, 1985; Clifford y Marcus (comps.), Writing, 1986; Geertz et al., Surgimiento, 1996; Berkhofer, Jr., Beyond, 1997, y White, Tropics, 1986.
-Álvarez Curbelo, Silvia, "El afán de la modernidad: La constitución de la discursividad moderna en Puerto Rico (siglo XIX)", tesis doctoral, Departamento de Historia, Universidad de Puerto Rico-Río Piedras, 1998.

-Baerga, María del Carmen (comp.), Género y trabajo: la industria de la aguja en Puerto Rico y el Caribe bispánico, Editorial de la Universidad de Puerto Rico, San Juan, 1993.

-Baldrich, Juan José, Sembraron la no siembra: Los cosecheros de tabaco puertorriqueños frente a las corporaciones tabacaleras, 1920-1934, Ediciones Huracán, Río Piedras, 1988.

-Baralt, Guillermo A., Esclavos rebeldes: conspiraciones y sublevaciones de erclavos en Puerto Rico, 1795-1873, Ediciones Huracán, Río Piedras, 1982.

-Barceló Miller, María de Fátima, La lucha por el sufragio femenino en Puerto Rico, 1896-1935, Ediciones Huracán/Centro de Investigaciones Sociales-UPR, Río Piedras, 1997.

-Barnet, Miguel, Biografía de un cimarrón, Centro Editor de América Latina, Buenos Aires, 1979.

-Beckles, Hilary McD., "An economic life of their own: Slaves as commodity producers and distributors in Barbados" en Ira Berlin y Philip D. Morgan (comps.), The Slaves' Economy: Independent Production by Slaves in the Americas, Frank Cass, Londres, 1991, pp. 31-47.

- Natural Rebels: A Social History of Enslaved Black Women in Barbados, Rutgers University Press, New Brunswick, NJ, 1989.

-Berkhofer, Jr., Robert F., Beyond the Great Story: History as Text and Discourse, The Belknap Press of Harvard University Press, Cambridge, Mass., 1997.

-Biblioteca de clásicos dominicanos, vol. IV: Oviedo/Las Casas, Crónicas escogidas, Fundación Corripio, Santo Domingo, 1988. 


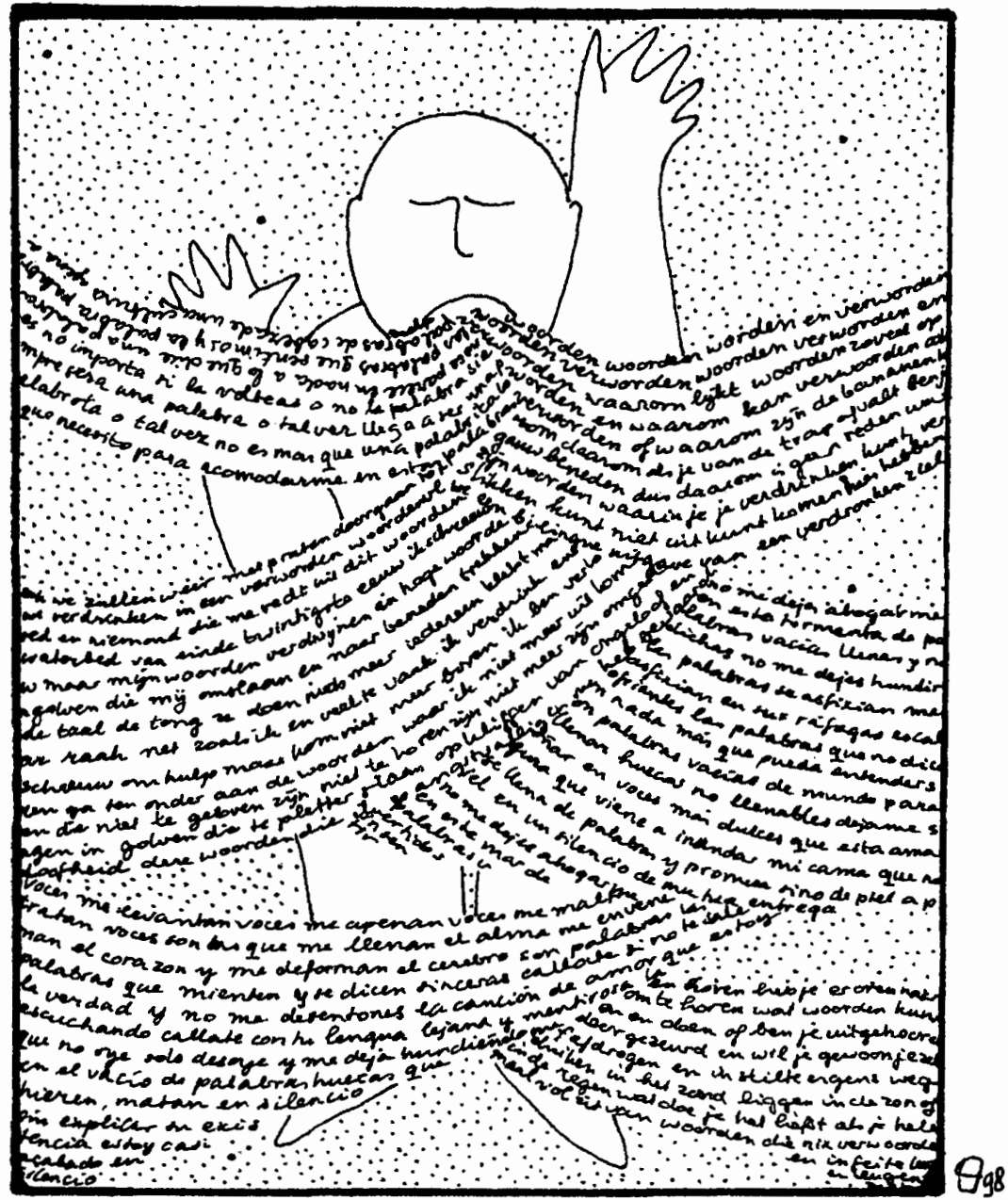


-Bosch, Juan, "Un pueblo en un libro" [1940] en Juan I. Jimenes Grullón, La República Dominicana: análisis de su pasado y su presente, Editora Cosmos, 3a ed., Santo Domingo, 1974, pp. 7-15.

-Bush, Barbara, Slave Women in Caribbean Society, 1650-1838, Heinemann Publishers/ Indiana University Press/James Curry, Kingston/Bloomington/Londres, 1990.

-Cabrera, Olga, Los que viven por sus manos, Editorial de Ciencias Sociales, La Habana, 1985 .

- El movimiento obrero cubano en 1920, Instituto del Libro, La Habana, 1969.

-Campbell, Mavis C., The Maroons of Jamaica, 1655-1796: A History of Resistance, Collaboration and Betrayal, Africa World Press, Trenton, NJ, 1990.

-Caro Costas, Aida, Antología de lecturas de bistoria de Puerto Rico (siglos XV-XVIII), Edición de la autora, 2a ed., San Juan, 1983.

Cassá, Roberto, Los indios de las Antillas, Editorial MAPFRE, Madrid, 1992.

- Movimiento obrero y lucha socialista en la República Dominicana (Desde los orígenes hasta 1960), Fundación Cultural Dominicana, Santo Domingo, 1990.

-Castro, María de los Ángeles “De Salvador Brau a la 'novísima historia': un replanteamiento y una crítica", op. cit.: Boletín del Centro de Investigaciones Históricas, núm. 4, 1988-1989, pp. 9-35.

-Clifford, James y George E. Marcus (comps.), Writing Culture: The Poetics and Politics of Ethnography, University of California Press, Berkeley, 1986.

-Craton, Michael, Testing the Chains: Resistance to Slavery in the British West Indies, Cornell University Press, Ithaca, NY, 1982.

-Cross, Malcolm y Gad Heuman (comps.), Labour in the Caribbean: From Emancipation to Independence, Warwick University Caribbean Studies, Londres, 1988.
-Davis, David Brion, The Problem of Slavery in the Age of Revolution, 1770-1823, Cornell University Press, Ithaca, NY, 1975.

, The Problem of Slavery in Western Culture, Cornell University Press, Ithaca, NY, 1966.

- Slavery and Human Progress, Oxford University Press, Nueva York, 1984.

-De Certeau, Michel, La escritura de la bistoria, Universidad Iberoamericana, México, 1985.

-Deive, Carlos Esteban, Vodú y magia en Santo Domingo, Fundación Cultural Dominicana, 2a ed., Santo Domingo, 1988.

-Duarte Hurtado, Martín, La máquina torcedora de tabaco y las luchas en torno a su implantación en Cuba, Editorial de Ciencias Sociales, La Habana, 1973.

-Eisner, Gisela, Jamaica, 1830-1930: A Study in Economic Growth, Greenwood Press, Westport, Conn., 1974.

-Elkins, Stanley M., Slavery: A Problem in American Institutional \& Intellectual Life, Universal Library, Nueva York, 1963.

-Fanon, Frantz, Los condenados de la Tierra, Fondo de Cultura Económica, 2a ed., México, 1972.

-...., , Escucha, blanco!, Editorial Nova Terra, 2a ed., Barcelona, 1970.

-Fernández Méndez, Eugenio (comp.), Crónicas de Puerto Rico: desde la conquista basta nuestros días, 1493-1955, Editorial de la Universidad de Puerto Rico, 2a ed., Río Piedras, 1970.

-Findlay, Eileen J., "Love in the tropics: Marriage, divorce, and the construction of benevolent colonialism in Puerto Rico, 1898-1910" en Gilbert M. Joseph, Catherine C. Legrand y Ricardo D. Salvatore (comps.), Close Encounters of Empire: Writing the Cultural History of U.S.-Latin American Relations, Duke University Press, Durham, 1998, pp. 139-172. 
-Flores Ramos, José, "Virgins, whores, and martyrs: Prostitution in the colony, 1898-1919", en Félix V. Matos Rodríguez y Linda C. Delgado (comps.), Puerio Rican Women's History: New Perspectives, M. E. Sharpe, Armonk, NY, 1998, pp. 83-104.

-Foner, Laura y Eugene D. Genovese (comps.), Slavery in the New World: A Reader in Comparative History, Prentice-Hall, Englewood Cliffs, NJ, 1969.

-Fouchard, Jean, Le marrons de la liberté, Editions Henri Deschamps, Port-au-Prince, 1988.

-García, Gervasio L. y A. G. Quintero Rivera, Desafío y solidaridad: breve historia del movimiento obrero puertorriqueño, Ediciones Huracán, Río Piedras, 1982.

-Geertz, Clifford et al., El surgimiento de la antropología posmoderna, Gedisa, 3a ed., Barcelona, 1996.

-Genovese, Eugene D., Economía política de la esclavitud: estudios sobre la economía y la sociedad en el Sur esclavista, Editorial Península, Barcelona, 1970.

- From Rebellion to Revolution: Afro-American Slave Revolts in the Making of the New World, Vintage, Nueva York, 1981. - Roll, Jordan, Roll: The World the Slaves Made, Vintage, Nueva York, 1976.

- The World the Slaveholders Made: Two Essays in Interpretation, Vintage, Nueva York, 1971.

-González, José Luis, "Literatura e identidad nacional en Puerto Rico" en Ángel Quintero Rivera et al., Puerto Rico: identidad nacional y clases sociales, Ediciones Huracán, Río Piedras, 1979, pp. 45-79.

-González, Lydia Milagros y A. G. Quintero Rivera, La otra cara de la bistoria: la bistoria de Puerto Rico desde su cara obrera, vol. I: 1800-1925, Centro de Estudios de la Realidad Puertorriqueña, Río Piedras, 1984.
-Guha, Ranajit, "On some aspects of the historiography of colonial India" en Ranajit Guha y Gayatri Chakravorty Spivak (comps.), Selected Subaltern Studies, Oxford University Press, Nueva York, 1988, pp. 37-44.

-Hall, Douglas, Free Jamáica, 18381865: An Economic History, Yale University Press, New Haven, 1959.

-Hart, Richard, Esclavos que abolieron la esclavitud, Casa de las Américas, La Habana, 1984

-Henry, Paget y Paul Buhle (comps.), $C$. $L$. $R$. James's Caribbean, Duke University Press, Durham, 1992.

-Higman, B. W., "Patterns of exchange within a plantation economy: Jamaica at the time of emancipation", en Roderick A. McDonald (comp.), West Indies Accounts: Essays on the History of the British Caribbean and the Atlantic Economy in Honour of Richard Sheridan, The Press-University of the West Indies, Kingston, 1996, pp. 211-231.

-Hobsbawm, Eric, Primitive Rebels: Studies in Archaic Forms of Social Movement in the 19th and 20th Centuries, Norton, Nueva York, 1965.

-Holt, Thomas, The Problem of Freedom: Race, Labor, and Politics in Jamaica and Britain, 1832-1938, Johns Hopkins University Press, Baltimore, 1992.

-Klein, Herbert S., Slavery in the Americas: A Comparative Study of Virginia and Cuba, University of Chicago Press, Chicago, 1967.

-Knight, Franklin W., "Race, ethnicity and class in Caribbean history" en General History of the Caribbean, vol. vi: Methodology and Historiograpby of the Caribbean, ed. por Barry Higman, UNESCO Publishing/Macmillan Education, Londres y Oxford, 1999, pp. 200-232.

-Haraksingh, Kusha, "Labour movements in Caribbean history" en General History of the Caribbean, vol. vI: Methodology and Histo- 
riography of the Caribbean, ed. por Barry Higman, UNESCO Publishing/Macmillan Education, Londres y Oxford, 1999, pp. 283-307.

-Legrand, Catherine C., "Informal resistance on a Dominican sugar plantation during the Trujillo dictatorship", Hispanic American Historical Review, vol. 75, núm. 4, 1995, pp. 555-596.

-Lugo-Ortiz, Agnes I., Identidades imaginadas: biografía y nacionalidad en el borizonte de la guerra (Cuba 1860-1898), Editorial de la Universidad de Puerto Rico, San Juan, 1999.

-Marshall, Woodville K., "Peasant development in the West Indies since 1838", en Hilary Beckles y Verene Shepherd (comps.), Caribbean Freedom: Economy and Society from Emancipation to the Present, Ian Randle y James Currey, Kingston y Londres, 1993, pp. 99-106.

"Provision ground and plantation labour in four Windward Islands: Competition for resources during slavery", Slavery and Abolition, núm. 12, 1991, pp. 48-67.

-Martínez, Lusitania, Palma Sola: opresión y esperanza (Su geografía mítica y social), Centro Dominicano de Estudios de la Educación, Santo Domingo, 1991.

-Martinez-Alier, Verena, Marriage, Class and Colour in Nineteenth-Century Cuba: A Study of Racial Attitudes and Sexual Values in a Slave Society, Cambridge University Press, Cambridge, 1974.

-Martínez Peláez, Severo, La patria del criollo: ensayo de interpretación de la realidad colonial guatemalteca, Editorial Universitaria Centroamericana, 3a ed., San José, 1975.

-Matos Rodríguez, Félix V., Women and Urban Change in San Juan, Puerto Rico, 1820 1868, University Press of Florida, Gainesville, 1999.

-Memmi, Albert, Retrato del colonizado. Precedido por Retrato del colonizador, Ediciones de la Flor, Buenos Aires, 1969.
-Mintz, Sidney, Caribbean Transformations, Johns Hopkins University Press, Baltimore, 1984.

-Patterson, Orlando, The Sociology of Slavery: An Analysis of the Origins, Development and Structure of Negro Slave Society in Jamaica, Macgibbon \& Kee, Londres, 1967.

-Picó, Fernando, Al filo del poder: subalternos y dominantes en Puerto Rico, 1739-1910, Editorial de la Universidad de Puerto Rico, San Juan, 1993.

- Amargo café: los pequeños y medianos caficultores de Utuado en la segunda mitad del siglo XIX, Ediciones Huracán, Río Piedras, 1981.

- Libertad y servidumbre en el Puerto Rico del siglo XIX: los jornaleros utuadeños en vísperas del auge del café, Ediciones Huracán, 3a ed., Río Piedras, 1983.

Price, Richard, Alabi's World, Johns Hopkins University Press, Baltimore, 1990. - First Time: The Historical Vision of an Afro-American People, Johns Hopkins University Press, Baltimore, 1983. (comp.), Marron Societies: Rebel Slave Communities in the Americas, Anchor Press/Doubleday, Garden City, Nueva York, 1973.

-Price-Mars, Jean, Así babló el tío, trad. de Virgilio Piñera y prólogo de René Depestre, Casa de las Américas, La Habana, 1968. -Quintero Rivera, Ángel G., Conflictos de clase y política en Puerto Rico, Ediciones Huracán, Río Piedras, 1976.

-, Patricios y plebeyos: burgueses, bacendados, artesanos y obreros. Las relaciones de clase en el Puerto Rico de cambio de siglo, Ediciones Huracán, Río Piedras, 1988.

-Quiñones Arocho, María I., "Sin hombre en la casa: el mito del matriarcado en el Caribe angloparlante" en Mario R. Cancel (comp.), Historia y género: vidas y relatos de $m u$ jeres en el Caribe, Asociación Puertorriqueña 
de Historiadores/Postdata, San Juan, 1997, pp. 30-42.

-Ramos Mattei, Andrés A., La sociedad del azúcar en Puerto Rico, 1870-1910, Universidad de Puerto Rico, Río Piedras, 1988.

-Rodney, Walter, A History of the Guyanese Working People, 1881-1905, Johns Hopkins University Press, Londres, 1981.

-Rodríguez Santana, Ivette, "Las mujeres y la higiene: la construcción de 'lo social' en San Juan, 1880-1929" en Mario R. Cancel (comp.), Historia y género: vidas y relatos de mujeres en el Caribe, Asociación Puertorriqueña de Historiadores/Postdata, San Juan, 1997, pp. 80-95.

-San Miguel, Pedro L., Los campesinos del Cibao: economía de mercado y transformación agraria en la República Dominicana, 18801960, Editorial de la Universidad de Puerto Rico, San Juan, 1997.
L_ "Falsos (además de confusos) comienzos de una digresión sobre historia y antropología", op. cit.: Revista del Centro de Investigaciones Históricas, núm. 11, 1999, pp. 33-61.

La isla imaginada: bistoria, identidad y utopia en La Española, Editorial Isla Negra/Librería La Trinitaria, San Juan y Santo Domingo, 1997.

, El mundo que creó el azúcar: las baciendas en Vega Baja, 1800-1873, Ediciones Huracán, Río Piedras, 1989.

, El pasado relegado: estudios sobre la bistoria agraria dominicana, Librería La Trinitaria/FLACSO/DEGI-UPR, Santo Domingo, 1999.

-Scarano, Francisco, "Slavery and emancipation in Caribbean history" en General History of the Caribbean, vol. vi: Metbodology and Historiography of the Caribbean, ed. por Barry

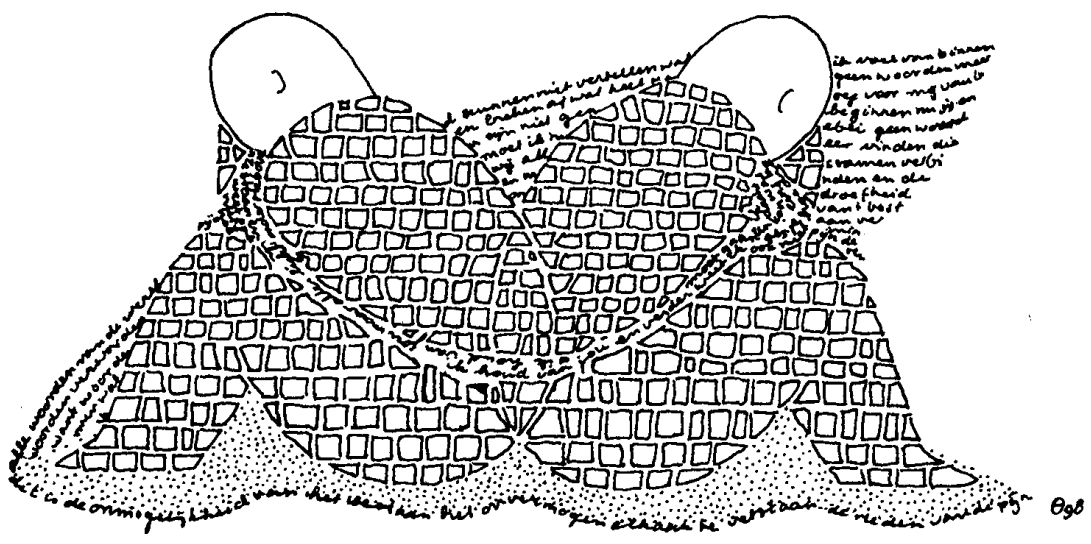


Higman, UNESCO Publishing/Macmillan Education, Londres y Oxford, 1999, pp. 233-282.

-Schuler, Monica, "Myalism and the African religious tradition in Jamaica" Margaret E. Crahan y Franklin W. Knight (comps.), Africa and the Caribbean: The Legacies of a Link, Johns Hopkins University Press, Baltimore, 1980, pp. 65-79.

-Scott, James C., Domination and the Arts of Resistance: Hidden Transcripts, Yale University Press, New Haven, 1990.

$\longrightarrow$ Weapons of the Weak: Everyday Forms of Peasant Resistance, Yale University Press, New Haven, 1985.

-Scott, Rebecca J., Slave Emancipation in Cuba: The Transition to Free Labor, 18601899, Princeton University Press, Princeton, 1985.

-Sosa Rodríguez, Enrique, Los ñáñigos, Casa de las Américas, La Habana, 1982.

-Spivak, Gayatri Chakravorty, "Subaltern studies: Deconstructing historiography" en Ranajit Guha y Gayatri Chakravorty Spivak (comps.), Selected Subaltern Studies, Oxford University Press, Nueva York, 1988, pp. 3-32

-Steward, Julian et al., The People of Puerto Rico: A Study in Social Antbropology, University of Illinois Press, Urbana, Ill., 1966.
-Stubbs, Jean, "Gender in Caribbean history" en General History of the Caribbean, vol. vi: Methodology and Historiography of the Caribbean, ed. por Barry Higman, UNEsCO Publishing/Macmillan Education, Londres y Oxford, 1999, pp. 95-135.

- Tabaco en la periferia: el complejo agro-industrial cubano y su movimiento obrero, 1860-1959, Editorial de Ciencias Sociales, La Habana, 1989.

-Taller de Formación Política, $;$ Huelga en la caña!: 1933-34, Ediciones Huracán, Río Piedras, 1982.

-Tannenbaum, Frank, Slave \& Citizen: The Negro in the Americas, Vintage, Nueva York, 1946.

-Thompson, E. P., The Making of the English Working Class, Vintage, Nueva York, 1966.

- Tradición, revuelta y conciencia de clase: estudios sobre la crisis de la sociedad preindustrial, Editorial Crítica, Barcelona, 1979.

-VV. AA., Los obreros bacen y escriben su bistoria: selección de trabajos presentados al Primer Encuentro de Historia del Movimiento Obrero Cubano, Editorial de Ciencias Sociales, La Habana, 1975.

-White, Hayden, Tropics of Discourse: Essays in Cultural Criticism, Johns Hopkins University Press, Baltimore, 1986. 